\title{
The Number of Beams and Their Arrangement in The Intensity Modulated Radiotherapy for Prostate Cancer
}

\author{
A.E. Amin, M.H. Abdel gawad, E.M. El-Sayed* and K.E. \\ Nasr \\ Ain shams Oncology Center, Faculty of Medicine and \\ *Biophysics Branch, Physics Dept., Faculty of Science, Ain- \\ shams University, Cairo, Egypt.
}

\begin{abstract}
7 HIS STUDY presents a certain set of optimal physical parameters applied to the prostate cancer cases treated with the intensitymodulated radiotherapy (IMRT) technique. Generally, the physical parameters include the beam energy, number of beams, beam arrangement and the optimal segmentation. In this work, we focused on the role of the number of beams and the beam arrangement applied to enhance the IMRT plan. Three prostate cases with different PTV volume and Precise Elekta ${ }^{\circledR}$ planning were studied and 33 plans with different number of beams and different angles were applied to identify the starting point in the optimal parameters. The obtained results had showed that in prostate cancer cases the D98 of prescribed PTV dose can be achieved with up to nine beams with accepted D30 of rectum and accepted $\mathrm{D}_{\text {mean }}$ of femoral heads. The odd number of beams has an advantage over the even numbers of beams for getting a lower dose in the organs at risk, (OARs). The odd number of beam with equally spaced angles showed achievable results better than that when these beams were arranged with un-equally spaced angels while in the case of even number the results were different.
\end{abstract}

Keywords : Radiotherapy, Treatment planning system (TPS), Intensity modulated Radiotherapy (IMRT).

IMRT is used in many radiotherapy departments for a variety of tumor sites. Because it irradiates tumors while simultaneously sparing organs at risk as well as) OARs) adjacent to the planning target volume (PTV) ${ }^{(1)}$. Using intensity modulated rather than uniform intensity beams, the planner has far more control to structure the shape of the dose distribution as a function of the shape of the planning target volume (PTV) and its anatomical relations to organs-at-risk (OARs). Some dose distributions cannot be obtained with uniform intensity beams and have suitable characteristics to increase the therapeutic ratio of radiotherapy for certain tumor sites ${ }^{(2)}$. Inverse planning yields modulated intensity distributions introduced by Bortfeld et al. ${ }^{(3)}$ in the early 1990s.

The whole IMRT process is comprised of several critical stages. Starting from CT-scanning, registration of the patient anatomy to allow accurate repositioning, image data transfer to the treatment planning system, target 
definition, treatment planning (often with inverse planning), transfer of the plan to the treatment machine, setting up of the patient to the predetermined position with respect to isocenter, delivery of the planned treatment in an automated sequence of a large number of MLC-shaped fields from different gantry angles and finally repeating the patient setup and dose delivery with high accuracy. These steps take a lot of time to be done, so that, the patient's planning step is one of the very important steps to build the remaining process. This step depends on the treatment planning system which depends on the physical parameters ; including the number of beams, beam energy, beams arrangement and segmentation optimizing. These parameters should be determined before the planning process. In this study, we present only the role of the number of beams and beam arrangement in the enhancement of IMRT plan in prostate cases.

Bortfeld $^{(4)}$ had reported theoretically that the required number of beams depends directly on the complexity of the fluency (intensity) profiles that can be delivered within the physical and technical constraints of the treatment machine. In realistic cases, in which the variability of the lateral dose profile is restricted in several ways, the required number of beams is of the order of 10-20 .The fluence variability depends, in turn, on the complexity of the dose prescription and is therefore case dependent. However, even the most complex cases do not benefit from an arbitrarily high number of beams. This is so because there is also a physical limit on the achievable amount of fluence (or rather dose) modulation, which is due to the scattering dose.

In another study by Margie et al. ${ }^{(5)}$, they mentioned that, the ability to modulate the beam intensity within a field could partially compensate for a relatively poor choice of beam directions and the complexity of treatment often increases as more fields are used. In clinical situations and in the presence of significant target concavities, five to nine uniformly spaced, non-coaxial or, if beneficial, non-coplanar fields, often yield clinically acceptable dose distributions.

When selecting IMRT beam directions, we should pay attention to unconstrained normal tissues in the path of the beams. These tissues may receive unacceptably high doses during optimization that was noticed through careful review of dose distributions and dose volume data . In the study by Chung et al. ${ }^{(6)}$, the recommendation in IMRT prostate plan was using seven relatively equally spaced coplanar beams $\left(0^{\circ}, 50^{\circ}, 100^{\circ}, 150^{\circ}, 210^{\circ}, 260^{\circ}\right.$ and $\left.310^{\circ}\right)$ to achieve better target coverage than what is achieved by irregularly spaced beams .

The resulting fluency distributions have to be converted to deliverable beam segments and hence to leaf positions. The leaf arrangement is subjected to many technical constraints, often resulting in an altered fluency matrix. ${ }^{(1)}$

As we mentioned above, there are many studies in the planning systems aiming to detect the helpful methods. Therefore, in this study we are looking for the role of number of beams in the enhancement of prostate IMRT planning .

Egypt. J. Biophys. Biomed. Engng. Vol. 16 (2015) 


\section{Materials and Methods}

We selected patients from the treatment list of Ain Shams Oncology Center one year ago. In this study, patients who had prostate cancer were divided into three groups according to their size. These groups included small patients, medium patients and large patients. Patients were distributed among these groups according to the patient's anterior-posterior separation. The ranges of anteriorposterior separation were less than $20 \mathrm{~cm}, 20$ to $24 \mathrm{~cm}$ and more than $24 \mathrm{~cm}$ for small patient group, medium patient group \& large patient group, respectively . We selected three cases (one from each group), the separation of first case was $20 \mathrm{~cm}$ as a small case and the second was about $23 \mathrm{~cm}$ as a medium case while the third case was $26 \mathrm{~cm}$ as a large case. The aim is to study the influence of the number of beams and arrangement in each patient's group .

CT images had $5 \mathrm{~mm}$ spacing over the entire treatment area .Only one treatment volume (PTV) and other organs at risk (OARs) were defined, the planning target volume (PTV) included (Gross tumor volume + seminal vesicles + margin $(1 \mathrm{~cm}$ anteriorly and $0.6 \mathrm{~cm}$ posterior $))$. In this study, the OARs are rectum, bladder and both femoral heads .

Precise @ planning System (version 1.13 Elekta medical systems (was used in this study to perform the inverse planning . Precise ${ }^{\circledR}$ planning System in this calculation process depends on the measurements of physical $\&$ geometrical data of precise $®$ Linear Elekta for both $6 \& 15 \mathrm{MV}$ photon energies .

We are aiming in this study to detect the optimal number of beams by trying multi plan with the same constrains, where, we used only the dose constrains of the first treatment phase of prostate cancer. The prescribed dose in this treatment course was 58 Gy by 2 Gy/fraction, 6 weeks. The constrains of the inverse planning are shown in Table $1^{(7)}$.

TABLE 1. Dose constrains of target and OAR of phase I in IMRT prostate case.

\begin{tabular}{|l|c|c|c|c|}
\hline \multicolumn{1}{|c|}{ Structure } & $\begin{array}{c}\text { Prescribed dose } \\
\text { (cGy) }\end{array}$ & $\begin{array}{c}\text { Mean dose } \\
\text { (cGy) }\end{array}$ & $\begin{array}{c}\text { Under dose } \\
\text { (cGy) }\end{array}$ & $\begin{array}{c}\text { Over dose } \\
\text { (cGy) }\end{array}$ \\
\hline PTV & 5797 & & 5507 & 6203 \\
\hline Bladder & & 3500 & & 5500 \\
\hline Rectum & & 3000 & & 5000 \\
\hline Heads of femur & & 3000 & & 4500 \\
\hline
\end{tabular}

The dose volume histograms (DVHs) of the PTV and all OARs were calculated. From DVH of the PTV the $\mathrm{D}_{98}$ (the minimum absorbed dose that covers $98 \%$ of the volume of the PTV) was estimated. For both bladder and rectum, the $\mathrm{D}_{30}$ (the absorbed dose that covers $30 \%$ of the volume) of the bladder and rectum were estimated from their DVHs. The mean absorbed dose 
(Dmean ) of the femoral heads were also estimated. These dose values were used in the comparison of the different treatment plans ${ }^{(8)}$. In this study, the 6MV have been used in all trial plans. For each case, we used ${ }^{(11)}$ plans. Table 2 shows the description of these plans:

TABLE 2. The physical parameters with the different treatment plans.

\begin{tabular}{|c|c|l|}
\hline \multirow{2}{*}{ Plan no. } & \multicolumn{2}{|c|}{ The physical parameters } \\
\cline { 2 - 3 } & No. of beams & \multicolumn{1}{c|}{ Beams arrangement } \\
\hline 1 & 15 & Equally spaced angles \\
\hline 2 & 14 & Equally spaced angles \\
\hline 3 & 13 & Equally spaced angles \\
\hline 4 & 12 & Equally spaced angles \\
\hline 5 & 9 & Equally spaced angles \\
\hline 6 & 7 & Equally spaced angles \\
\hline 7 & 7 & Equally spaced angles \\
\hline 8 & 6 & un-Equally spaced angles \\
\hline 9 & 6 & Equally spaced angles \\
\hline 10 & 5 & un-Equally spaced angles \\
\hline 11 & 5 &
\end{tabular}

As shown in Table 2 the (11) plans, which have been trials in this work, plans ( 1 to 5 ), have large number of beams: $15,14,13,12 \& 9$. The beams in these plans are equally spaced because of their large number and according the unavailability of space to change the beams arrangements; While plans (6 to 11) have low number of beams: $5,6 \& 7$, so that; these trial plans were performed once with equally spaced angles and once more with unequally spaced angles.

\section{Results and Discussion}

The results show that, for the three cases, plans number 1 to 5 did not record a big difference between them (the dose values are almost the same). Moreover, these plans lead to a more complex technique. The dose value of bladder and rectum were relatively the same in these plans but the dose value of femoral heads gradually decreased from 15 beams to 9 beams (Fig. 1 \& 2). The advantage of these techniques is the achievable homogeneous dose which appears in the dose value of PTV doses ( $\pm 5 \%$ of prescribed dose) but the disadvantages of these plans are not applicable due to the large number of beams which resulted in a large area of skin irradiation.

Egypt. J. Biophys. Biomed. Engng. Vol. 16 (2015) 


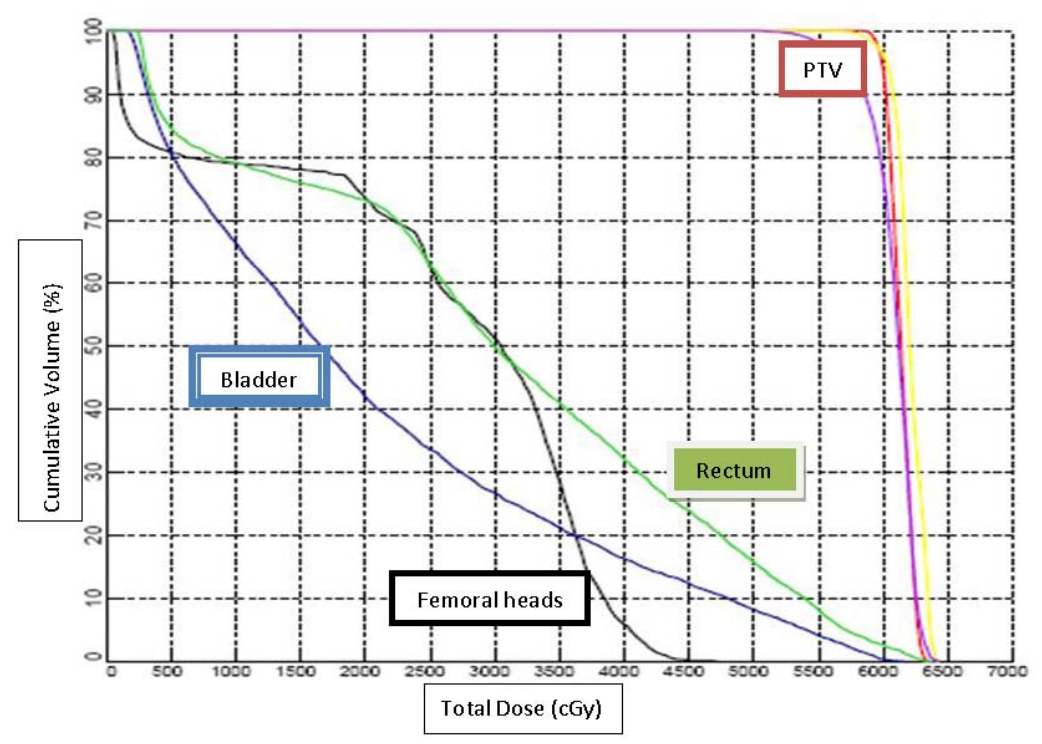

Fig. 1. DVH of plan with 15 Beams.

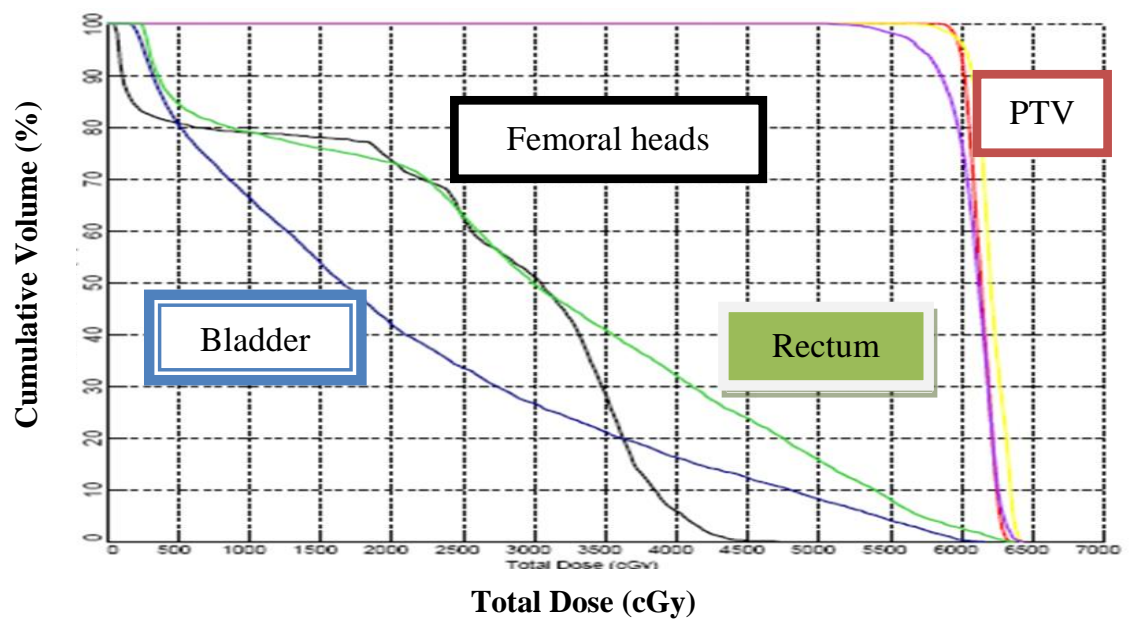

Fig. 2. DVH of plan with 9 beams.

In case of plans with low number of beams (plan no. 6 to 11), the results differ from the others, which had a large number of beams. In these plans, there are no restrictions to improve the plan because the small number of beams gives the facility to improve the plan by modifying the beam angle manually or modifying the beam segments. Therefore, the results of these plans may be better 
than other plans that utilized large number of beams. The small number of beams led to easy planning (not complex), shorter treatment time and smaller irradiated skin area. In case of odd number of beams (especially plans with 7 beams) yielded acceptable PTV and OAR dose values so in this case the planner didn't need to arrange the plan to be unequally spaced while in case of plans with 6 beams the results differed from one case to another due to the separation and dimensions of OARs. Plans with $6 \& 7$ beams yielded the highest total dose at $\mathrm{D}_{98}$ of the PTV. The preceding total dose was higher than plans with 5 beams while for the remaining OARs the $\mathrm{D}_{30}$ and Dmean of bladder and femoral heads were better in case of 5 beams than other techniques. Figure 3 to 5 show the DVHs of these plans.

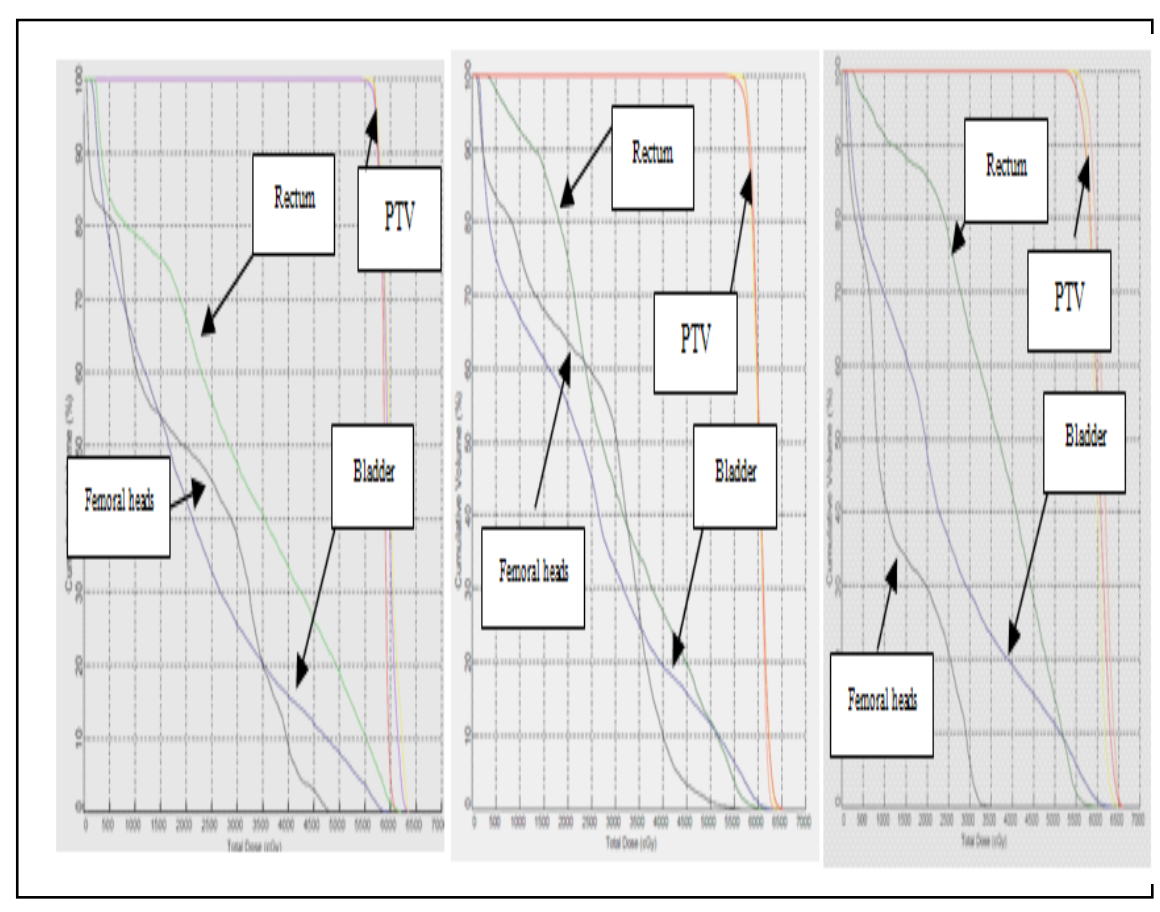

Fig.3. DVH of plan with 7 beams.

Fig.4. DVH of plan with Fig.5. DVH of plan with 6 beams. 5 beams.

Figures 6, 7 and 8 show the comparison between the plans that were applied to the $1^{\text {st }}, 2^{\text {nd }}$ and $3^{\text {rd }}$ case. 
THE NUMBER OF BEAMS AND THEIR ARRANGEMENT ...

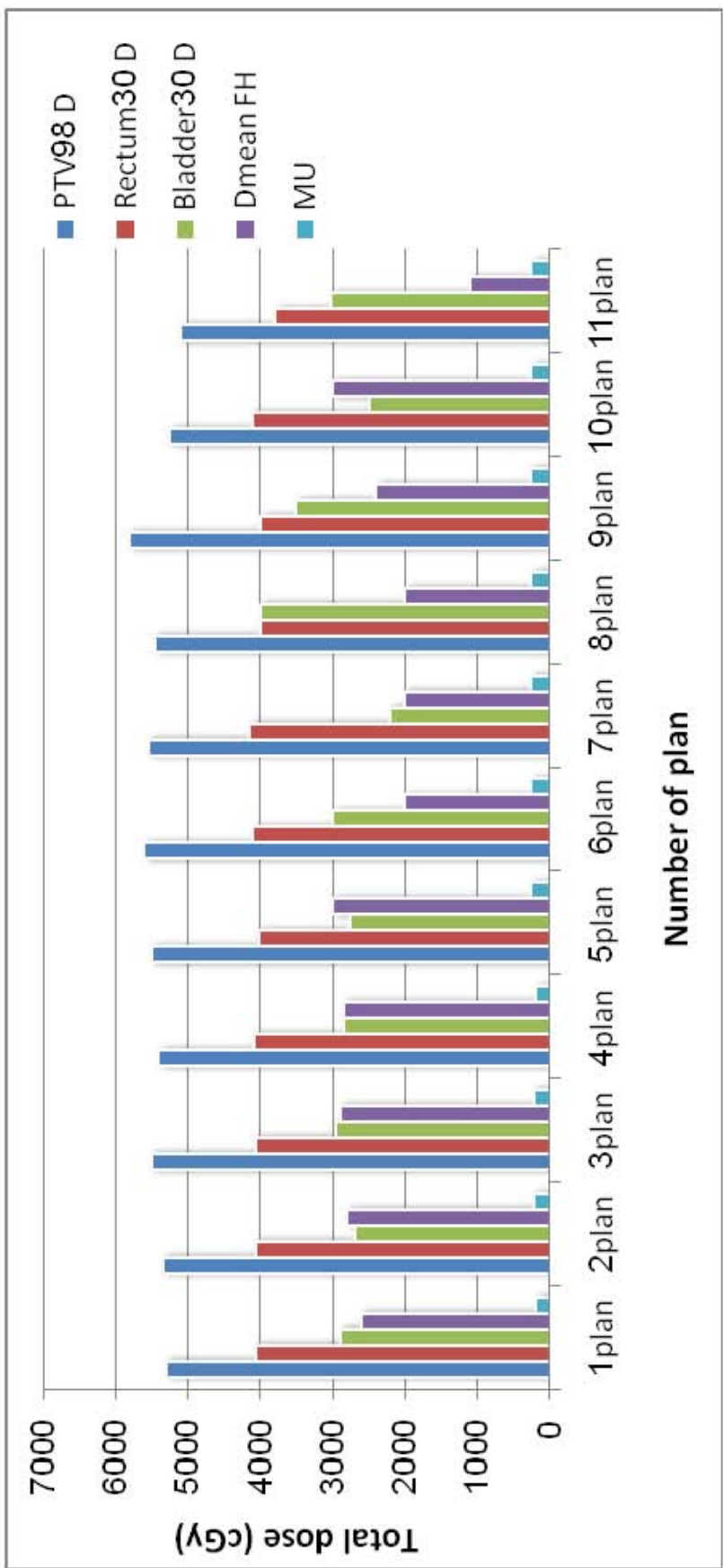

نं

Egypt. J. Biophys. Biomed. Engng. Vol. 16 (2015) 


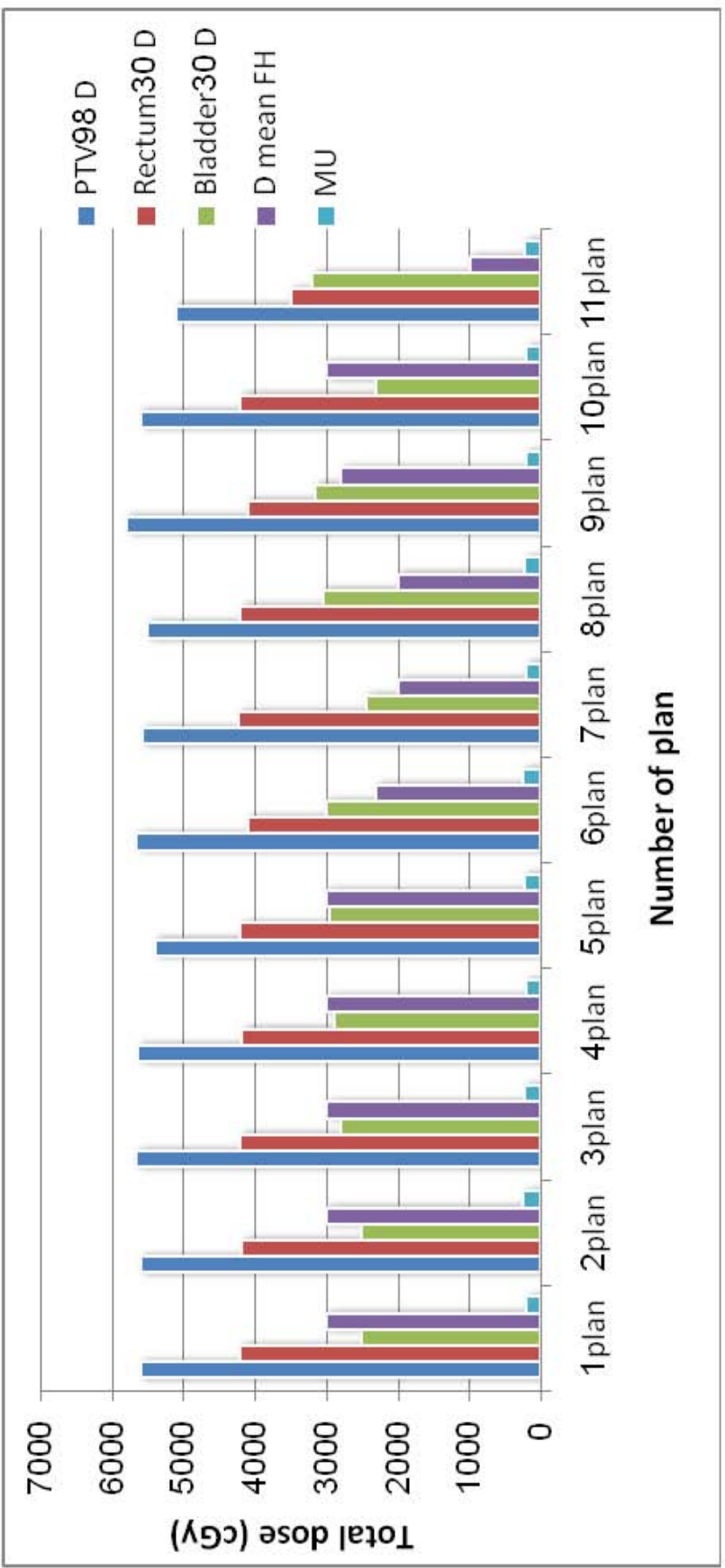




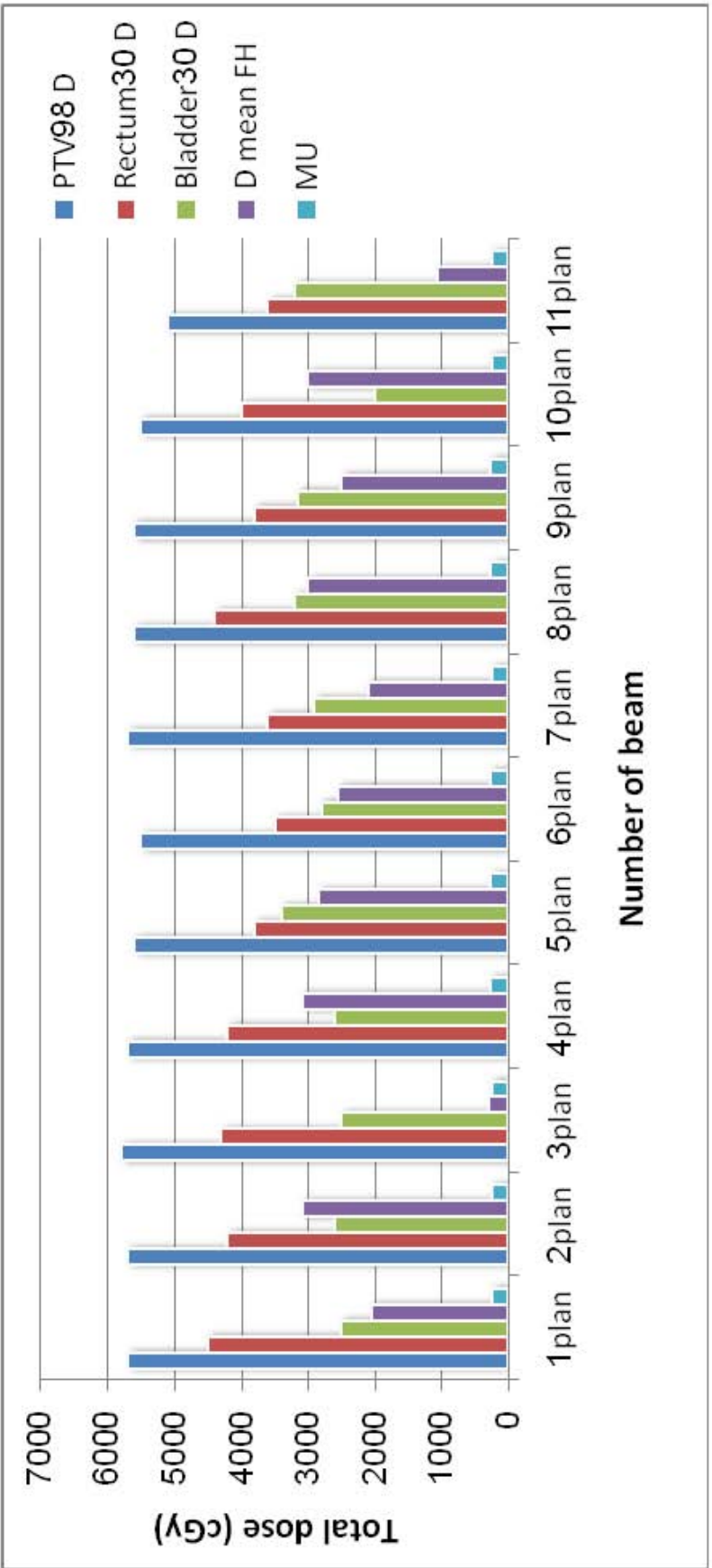

Uं

Egypt . J. Biophys. Biomed. Engng. Vol. 16 (2015) 
As shown in Fig. 6 and 7, the optimal plan is limited between plan no. 6 to 9 (plans with 6 or 7 beams equally and unequally spaced) in the first and second case. While Fig. 8 shows that the optimal plans are limited to plan no. 6 to 7 or 9 to 10 (plans with 7, 6 or 5 beams) in third case which can achieve about (95\% to $98 \%$ of the prescribed PTV dose) and achieve accepted dose value of OAR (rectum, bladder \& femoral heads). Based on these results the number of beams is not influenced by the patient size.

\section{Conclusion}

As we mentioned in the introduction, in a theoretical study by Bortfeld he reported that the required number of beams depends directly on the complexity of the fluency (intensity) profiles that can be delivered within the physical and technical constraints of the treatment machine and in realistic cases ,the required number of beams is of the order of 10-20.

While Margie showed that, the complexity of treatment often increases as more fields are used, So that; In the presence of significant target concavities, five to nine uniformly spaced, non-coaxial or, if beneficial, non-coplanar fields often yield clinically acceptable dose distributions.

The results of this study agree with Margie's results, as we concluded that the large number of beams (above nine beams) is not beneficial for the following reasons:

1. It is time consuming in both planning and treatment time.

2. Large number of beams cause larger irradiated areas of the skin and more scattered radiation.

The only advantage of using more than nine beams is its target dose homogeneity (D98 $\approx 96$ to $98 \%$ of prescribed PTV dose) and the lower dose value of the femoral heads (mean dose $\approx 43 \%$ of prescribed PTV dose). In spite of that, the target dose homogeneity produced from more than nine beams is not much better than that obtained from IMRT with less than nine beams (D98 $\approx 95$ to $97 \%$ of prescribed PTV dose). Also the odd number of beams had an advantage over the even number of beams by getting a lower dose in the OARs (see Figures 6, $7 \& 8$ ).

The beams arrangement mainly depends on the optimal direction (or gantry angle) that leads to decrease the effect of dose on the OARs; so that the beams arrangement is different from case to case. The results show that the plans with small and the odd number of beams give more accepted results than others with even and large number. As long as the small number is enough to getting an optimal plan, the beams arrangement (to be unequally or equally spaced) might not represent a problem to investigating the optimal plan. 


\section{References}

1. Klaus, B., Matthias, G. and Gerd, M., A comparison between 2-Step IMRT and conventional IMRT planning .Radiotherapy and Oncology,84,298-306 (2007).

2. Bortfeld, T., Rupert, S., Wilfred, D., David, E. and Wazer., image-Guided IMRT, Springer Berlin Heidelberg, pp.3-7 (2006).

3. Bortfeld, T., Burkelbach, J. and Boesecke, R., Methods of image reconstruction from projections applied to conformation radiotherapy. Phys. Med. Bio. 35, 1423-34 (1990).

4. Bortfield, T., The number of beams in IMRT-theoretical investigation and implications and implications for single-arc IMRT. Physics in Medicine and Biology, 55, 83-97 (2010).

5. Hunt, M., Burman, C.M. and Chandra, Treatment planning considerations using IMRT. Medical Physics for Radiation Therapy, 14, 103-119 (2004).

6. Chung, J., Lee, J., Kim, J., Kim, I. and Suh, T., The effect of photon beam energy on IMRT plan for prostate cancer: A Planning Study, Med. Phys. 38, 3692 (2011).

7. RTOG, “ Radiation terapy oncology group, P-0126, http://www.rtog.org. March 21 (2002)

8. ICRU, "International Commission on Radiation Unit and Measurements" Oxford University Press, Report 83, pp. 10 -1 (2010).

(Received 25/8/2014;

accepted $16 / 3 / 2015$ 


\section{عدد الحقول وتوزيعها فى العلاج الإشعاعى ذو الثدة المعدلة اللازمة فى علاج سرطان البروستاتا}

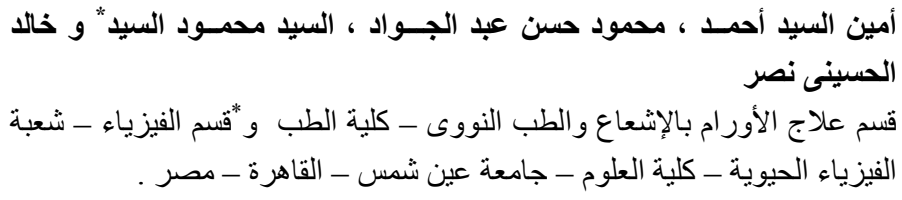

توضح هذه الدراسة أفضل البار اميترات الفيزيقية المستخدمة فى علاج سرطان

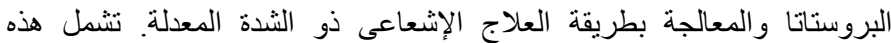

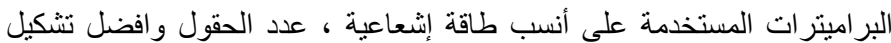
للحقيلات المنشأة ـ تم تسليط الضوء على دور البئر عدد الحقول اللازمة وترتيبها

لتحسين خطة العلاج الإشعاعى ذو الثدة المعدلة.

ثلاث حالات تم إختبار هم مختلفى الحجوم الورمية المر اد علاجها وتم استخدام

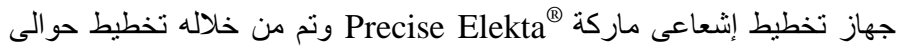
r بطة علاجية إثعاعية لكل حالة تختلف فيما بينها بناءا على على إختلاف

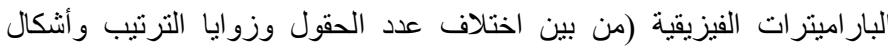
الحقيلات ) وذللك بهدف إختصار وقت الإختيار ا والوقوف على نقطة البهن البدأ المباشرة دون اللجوء إلى تجربة الأختيار ات الختاحة فئل ودئ بداية العلاج الإشعاعى.

النتائج المعطاة أوضحت أن حالات سرطان البروستاتا المراد علاجها يمكن

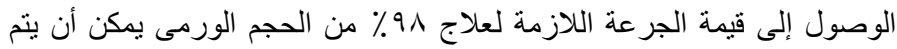

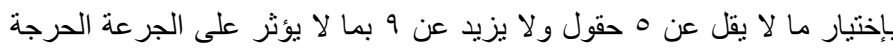

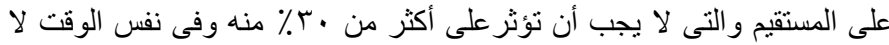

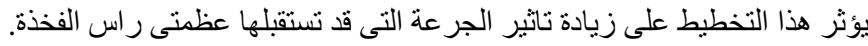

إختيار عدد الحقول له دور هام حيث ان إختيار عدد فردى من الحقول له فائدة

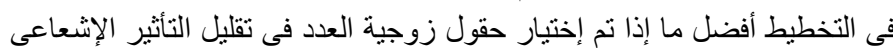

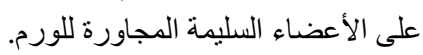

عدد الحقول الفردي وإختيار زوايا إثعاعية منساوية التوزيع حققت نتائج

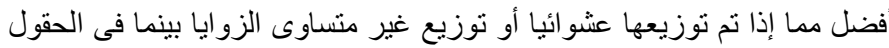
الزوجية قد تختلف النتائج. 